\title{
Um livro e seus usos: \\ Camões, Saramago e a escrita do Império
}

\author{
Silvio Renato Jorge \\ (Universidade Federal Fluminense)
}

\section{RESUMO}

Este artigo propõe uma leitura da peça Que farei com este lirro?, de José Saramago, a partir de suas relações intertextuais com os versos de Os Lusíadas. Ao acompanhar as dificuldades vividas pelo poeta para a publicação de sua epopeia, o texto contemporâneo retoma a discussão acerca do valor da obra literária ao mesmo tempo em que, a partir da análise de suas próprias contradições, indaga sobre o destino do Império português de então.

PALAVRAS-CHAVE: José Saramago, Os Lusíadas, Intertextualidade.

\section{ABSTRACT}

This article proposes a reading of the play Que farei com este liuro?, by José Saramago, from its intertextual relations with the verses of Os Lusiadas. While accompanying the difficulties experienced by the poet to publish his epic, the contemporary text returns to the debate about the value of literary work and, at the same time, from the analysis of its own contradictions, reflects upon the fate of the Portuguese Empire. KEYWORDS: José Sarmago, Os Lusíadas, Intertextuality. 
(...) ninguém pensa que as obras e os cantos poderiam ser criados do nada. Eles estão sempre ali, no presente imóvel da memória. Quem se interessaria por uma palavra nova, não transmitida? O que importa não é dizer, mas redizer e, nesse redito, dizer a cada vez, ainda, uma primeira vez.

Maurice Blanchot, Conversação infinita

É sobre redizer palavras que nos debruçamos hoje. Algumas interditas, outras repetidas com a frequência de quem busca, através delas, ser capaz de efetivar as imagens aí desveladas ou pressentidas. Sobretudo, buscamos palavras que, ditas de novo e sempre, ultrapassam a imobilidade do tempo para conquistar novos sentidos ou, ao menos, reativar aqueles que nelas ficaram esquecidos. Por isso, ao inquirirmos as palavras de Camões, procuramos encontrar não apenas o que conseguiram expressar ao seu tempo, mas o que ainda dizem, revelando-se capazes de ultrapassar fronteiras e prisões, de contornar o lugar sagrado em que foram imobilizadas para mostrarem-se renovadas em si mesmas, para apresentarem-se como um dizer a mais, incansável na capacidade de repelir qualquer leitura unívoca e redutora. É através dessas palavras que Camões permanece, e não apenas o poeta "brônzeo, monumental, guerreiro", a destacarse, no belo e angustiado olhar de Cesário, entre exíguas pimenteiras, como é dito naquele que talvez seja o mais significativo poema produzido no Portugal dos oitocentos, "O sentimento dum ocidental". Mas, também, permanece o poeta capaz de revelar os desconcertos de um mundo em constante transformação e as misérias inerentes ao próprio processo de existir, um poeta que um dia cantou:

Mudam-se os tempos, mudam-se as vontades.

Muda-se o ser, muda-se a confiança;

Todo o Mundo é composto de mudança,

Tomando sempre novas qualidades.

Continuamente vemos novidades,

Diferentes em tudo da esperança;

Do mal ficam as mágoas na lembrança,

E do bem (se algum houve...) as saudades.

O tempo cobre o chão de verde manto,

Que já coberto foi de neve fria,

E em mi $[\mathrm{m}]$ converte em choro o doce canto.

E, afora este mudar-se cada dia,

Outra mudança faz de mor espanto,

Que não se muda já como soia.

(CAMÕES, 1988, p.284)

É essa voz a revelar a voracidade do tempo e os caminhos tortuosos da experiência humana que vou procurar em um sábio leitor do poeta quinhentista, aquele que, sendo capaz de, ao citar suas palavras, sempre dizer uma primeira 
vez, também visitou sua estátua - como o fizera Cesário Verde, já o disse - para afirmar:

Ricardo Reis saiu, eram três menos um quarto, tempo de ir andando, atravessou a praça onde puseram o poeta, todos os caminhos portugueses vão dar a Camões, de cada vez mudado consoante os olhos que o vêem, em vida sua braço às armas feito e mente às musas dada, agora de espada na bainha, cerrado o livro, os olhos cegos, ambos, tanto lhos picam os pombos como os olhares indiferentes de quem passa. (SARAMAGO, 1986, p. 180)

Como disse, é Saramago sábio leitor de Camões. Sábio e constante, pois com ele dialoga não só n'O ano da morte de Ricardo Reis (1986) - em que encontramos o poeta a ver e a ser visto, tal qual o D. Sebastião de seu poema -, mas também em vários outros textos, como Levantado do chão (1982) e Memorial do convento (1983), buscando sempre um dizer a mais que, não seria errado afirmar, tem por principal preocupação despir o poeta das vestes com que um certo discurso imperialista o vestiu, para mostrar a fluência arguta de seu verbo, a capacidade de afirmar a inegável grandeza do feito - o sentido heroico de ultrapassar limites e questionar verdades - e, ao mesmo tempo, assinalar os descaminhos a que o homem e a pátria podem ser conduzidos por conta da cobiça e da rudeza "Dhia austera, apagada e vil tristeza" (Lus, X, 145). Na esteira do que Jorge de Sena e Cleonice Berardinelli já o disseram, ao afirmar o caráter plural da escrita camoniana, o seu inextricável transitar entre o ideológico e o contraideológico, José Saramago recupera o poeta naquilo que o discurso tem de corruptor, para, diante de sua grandeza, propor aos portugueses uma reflexão profunda acerca de seu lugar no mundo e do verdadeiro tamanho de seu quintal. Se lembro de Eduardo Lourenço a afirmar a necessidade de uma "nova viagem para esse outro desconhecido que somos nós mesmos e Portugal connosco" (LOURENÇO, 1988, p. 64) e a existência de uma imagem irreal acerca da história do país construída a partir da ficção d'Os Lusíadas, é por que acredito que o romancista contemporâneo, ao escrever a peça Que farei com este lirro? (1980) - e já aqui denuncio o principal objeto de minhas preocupações - parte dos versos presentes na estância 145 do canto dez a que atrás me referi, versos estes que talvez sejam os instrumentos mais agudos a revelar a irrealidade do Império sonhado, os pés de barro sobre os quais o sonho de grandeza fora construído.

E nunca é demais repetir:

No mais, Musa, no mais, que a Lira tenho

Destemperada e a voz enrouquecida,

E não do canto, mas de ver que venho

Cantar a gente surda e endurecida.

O favor com que mais se acende o engenho

Não no dá a pátria, não, que está metida

No gosto da cobiça e na rudeza

Dhia austera, apagada e vil tristeza. (Lus, X, 145)

É ao negar a continuidade do canto, logo após narrar a efetivação da conquista, que o autor da epopéia parece inscrever no tempo o questionamento levado adiante por Saramago no título de sua obra. Mais do que isso, parece 
também antecipar a pergunta que surgirá ao final da peça, nos lábios da personagem que recebe seu nome: "Que fareis com este livro?". Essa questão é sedutora e, como já o disse Teresa Cristina Cerdeira, torna-se responsável por "colocar em cena o texto de Os Lusíadas como livro fundador de uma cultura" (CERDEIRA, 2000 , p. 225). Seu sentido, em diálogo com o "No mais, Musa, no mais..." camoniano, sugere que, ao lermos o texto de Saramago, estamos diante de uma escrita que, para além de considerar o valor material do canto épico - ou seja, a grandiosidade daquilo que Camões, como poeta, foi capaz de produzir, e ainda a sua presença como um marco ${ }^{1}$ a indagar acerca do percurso português de ontem e de hoje - tem como ponto de partida não os versos grandiloquentes com que o poema se inicia - "As armas e os barões assinalados" - ou com que busca enfatizar as virtudes guerreiras dos reis e heróis portugueses, e cito:

\author{
Este é o primeiro Afonso (disse o Gama) \\ Que todo Portugal aos Mouros toma; \\ Por quem no Estígio lago jura a Fama \\ De mais não celebrar nenhum de Roma. \\ Este é aquele zeloso, a quem Deus ama, \\ Para cujo braço o Mouro immigo doma, \\ Pêra quem de seu Reino abaxa os muros, \\ Nada deixando já pêra os futuros. (Lus, VIII, 11)
}

Não... o ponto de partida de Que farei com este liıro? não é este. Nessa leitura que se vai agora construindo, ele está presente, sobretudo, naquilo que Cleonice Berardinelli chamou de “os excursos" do poeta n'Os Lusíadas, em texto incontornável para as nossas bibliografias (BERARDINELLI, 2000). Nesse texto, a pesquisadora destaca a presença, no poema épico, ao lado de um narrador responsável por simplesmente "narrar" a história que se conta, de uma segunda voz, eivada de lirismo, presente nas reflexões, exortações e queixas desenvolvidas nos comentários e que busca, especialmente, informar ao leitor acerca do modo como o poeta se relaciona com o objeto de seu canto e com o canto em si. Busca, ainda, conduzir o leitor a uma reflexão profunda acerca dos valores, virtudes e defeitos que circundam o homem e o escritor em sua existência histórica e terrena. É a essa voz - responsável, muitas vezes, por desestabilizar o caráter épico do texto e por relativizar o sentido do que é dito durante o processo de narração que o drama de Saramago irá recorrer, denunciando as injustiças da corte e o descaso dos poderosos para com a arte. Ao tecer-se como contra-dicção, recupera do texto camoniano personagens e passagens cuja presença encaminha a atenção do leitor para um espaço em que se faz marcante a indagação acerca do verdadeiro valor das viagens. Por isso, se n'Os Lusíadas encontramos um poeta e um velho apresentados como indivíduos a serem valorizados por possuírem um saber só de experiências feito, também em Que farei com este liuro? deparamo-nos com um "poeta velho" a dizer de si mesmo: "Não, minha mãe, não estou conformado. Vivo em Portugal. Sei o que a experiência me ensinou. Que assim como se diz que não há dinheiro que pague o talento e o engenho, também se deveria dizer que por isso mesmo ninguém os quer pagar" (SARAMAGO, 1980, p. 116). E também, se no poema épico é possível, ao leitor atento, surpreender a crítica ao herói e aos seus descendentes na voz do próprio narrador, quando este afirma que: 
Enfim, não houve forte Capitão

Que não fosse também douto e ciente,

Da Lácia, Grega ou Bárbara nação,

Senão da Portuguesa tão-somente.

Sem vergonha o não digo, que a rezão

De algum não ser por versos excelente

É não se ver prezado o verso e rima,

Porque quem não sabe arte, não na estima. (Lus, V, 97)

Como disse, se no poema épico é possível surpreender essa crítica, também no drama se torna possível observar o Conde de Vidigueira, apoiado em sua soberba, a desprezar o poeta e seu livro, a ponto de ser interpelado por este, quando pergunta: "Aonde irá morrer o conde de Vidigueira? Na hora de morrerdes, quem sabe se antes de mim, bom será que vos lembreis dessas palavras. É a última ocasião que tereis de pedir perdão a Deus por tê-las dito" (SARAMAGO, 1980, p. 82).

Como se vê, os olhos que investigam a relação entre o poeta e a pátria, entre o livro e o império, não se contentam com a idealização fugaz da viagem ou com a construção de "naus a haver". É necessário desvelar no outro tempo o que faz de hoje o tempo que é. Ao buscar na história o que não se contou - a demanda de Camões pela publicação de seu livro -, Que farei com este liuro? propõe outras indagações que acabam por inserir no texto questões que extrapolam a preocupação histórica e o recorte temporal aí estabelecido, recuperando para a cena dramática as angústias geradas pelo totalitarismo presente em Portugal no século XX. As indecisões próprias de um regime centralizador, a burocracia dos corredores do palácio, a censura decorrente da Inquisição e própria de um governo em que Estado e Religião se misturam - e que isto também sirva de lição para nós, brasileiros do Século XXI -, por fim, a representação de uma sociedade marcada não apenas pelo poder determinante dos bens materiais, mas, sobretudo, por uma hierarquização acentuada das relações de classe - todos estes fatores, em suma, acabam por propor um trânsito acentuado entre tempos distintos e por amplificar o papel do escritor no universo textual. Camões é aqui Camões, o próprio, mas também o Camões de Saramago e, ao mesmo tempo, uma representação metonímica de todo escritor. Por outro lado, se o livro é aqui recuperado como objeto de escrita, como manifestação da linguagem, ele também será percebido a partir da constatação da pluralidade de leituras que pode sofrer, acolhendo, ao mesmo tempo, um universo de significações que espelha a sua riqueza e, infelizmente, a sua vulnerabilidade. É a perspectiva do presente que permite a Que farei com este liuro? identificar a apropriação do texto camoniano por um universo ideológico que, se utilizando dos espaços abertos por sua riqueza, acaba por reduzi-lo a tudo aquilo que, provavelmente, o poeta não gostaria de ver. É também essa perspectiva que lhe permite denunciar esse processo para ultrapassá-lo através da escrita. Nas palavras da personagem:

Não o creio. Damião de Góis tinha razão. O meu livro é uma barca em que muitos querem navegar, desde que não embarquem nela outros. Se el-rei me quiser, não me quer o cardeal; se me quer o cardeal, não me há-de querer a rainha; se a rainha disser que sim, dirão os Câmaras que não... (SARAMAGO, 1980, p. 136) 
Desta forma, a demanda por publicar sua obra, iniciada de joelhos diante de um Rei que sequer olha para aquele que se submete ao seu poder, acaba por levar nosso cansado escritor à percepção do mundo que o cerca e das contradições inerentes desconcerto vivido: "Não pensou, não, que el-rei é mais inquisidor do que o inquisidor-mor" (SARAMAGO, 1980, p. 137). O mito do "Encoberto" é, com isto, desvelado pelo texto contemporâneo através de um D. Sebastião prepotente, cujo retrato será composto tanto por uma sexualidade ambígua quanto pela retomada irônica de elementos que marcam sua presença no imaginário lusitano: "Hoje, a manhã esteve de névoa. É de manhãs assim que el-rei mais gosta. É seu maior prazer cavalgar às cegas" (SARAMAGO, 1980, p. 22). Este rei que já se insinuara como o "Desejado" no corpo poético d'Os Lusíadas, através de versos como

E vós, ó bem nascida segurança

Da lusitana antiga liberdade,

E não menos certíssima esperança

De aumento da pequena Cristandade,

Vós, ó novo temor da Maura lança,

Maravilha fatal da nossa idade,

Dada ao mundo por Deus, que todo o mande,

Pera do mundo a Deus dar parte grande. (Lus, I, 6)

revela-se, no texto dramático, em um sentido profundo, como nevoeiro, como marca da impossibilidade de se perceber o caminho por que seguir, ao propiciar o envilecimento dos homens e obscurecer a imagem de um Império já corroído pela peste. A doença, que cerca Lisboa durante boa parte da peça, será associada por Ana de Sá à Índia, ao conversar com seu filho sobre a Inquisição. Por isso, a peste a corroer Portugal não é necessariamente apenas aquela que mata seus filhos de forma concreta nas terras banhadas pelo Tejo, mas também o sonho de ser maior do que verdadeiramente se é e a imposição de uma verdade alheia aos desejos dos homens. Ao perguntar $O$ que farei com este livro?, o poeta, transformado em linguagem por aquele que o diz - em linguagem dialogante e múltipla, pois que considera o seu discurso e o discurso do outro, através de um texto que mescla o dramático ao épico e ao lírico - tal poeta, como dizia, parece ir além do plano objetivo de sua interrogação para perguntar também acerca daquilo que o livro contém. Questionar o destino do livro é também, e por isso, estabelecer uma dúvida sobre o destino do Império, em seu caráter profundo e ideológico. É, talvez em primeiro lugar, indagar sobre o destino de um país que precisa, naquele momento, aprender um modo concreto de existência. E por isso, porque sois leitores já agora envolvidos nessa trama de referências, cabe a cada um de vós saber, portanto, "o que fareis com este livro". 


\section{NOTAS}

1. Creio ser importante lembrar que, quando digo marco, digo também monumento e, com isso, penso na estátua presente em "O sentimento dum ocidental" e em $O$ ano da morte de Ricardo Reis. Para o conceito de monumento, cf. LE GOFF, 1984, pp. 95-106.

\section{REFERÊNCIAS BIBLIOGRÁFICAS}

BERARDINELLI, Cleonice. Os excursos do Poeta n'Os Lusíadas. In: - Estudos camonianos. 2.ed. Revista e ampliada. Rio de Janeiro: Nova Fronteira, 2000, pp. 31-56.

CAMÕES, Luís de. Obra completa. Org. Antônio Salgado Jr. Rio de Janeiro: Nova Aguilar, 1988.

CAMÕES, Luís Vaz de. Os Lusíadas. Org. Emanuel Paulo Ramos. Porto: Porto Editora, 1982.

CERDEIRA, Teresa Cristina. História e memória cultural: José Saramago e a sedução camoniana. In: O aresso do bordado. Lisboa: Caminho, 2000, p. 224-229.

LE GOFF, Jacques. Documento / monumento. In: ENCICLOPÉDIA EINAUDI. Lisboa: IN-CM, 1984, v.1, p. 95-106.

LOURENÇO, Eduardo. Psicanálise mítica do destino português. In: O labirinto da saudade. 3.ed. Lisboa: Dom Quixote, 1988, p. 17-64.

SARAMAGO, José. Que farei com este livro? Lisboa: Caminho, 1980.

. Memorial do convento. São Paulo: Difel, 1982.

. Levantado do chão. São Paulo: Difel, 1983.

. O ano da morte de Ricardo Reis. 8.ed. Lisboa: Caminho, 1984. 